УДК 15(091)

К 90-ЛЕТИЮ СО ДНЯ РОЖДЕНИЯ ПРОФЕССОРА В.Г. БЕЛИКОВА

\author{
Б.В. Боровский, М.В. Ларский, О.О. Фролова \\ Пятигорский медико-фармачевтический институт - филиал ГБОУ ВПО ВолгГМУ \\ Минздрава России, г. Пятигорск
}

\title{
TO THE 90TH ANNIVERSARY OF BIRTHDAY OF PROFESSOR V.G. BELIKOV
}

\author{
B.V. Borovsky, M.V. Larsky, O.O. Frolova \\ Pyatigorsk Medical and Pharmaceutical Institute - \\ a branch of Volgograd State Medical University, Pyatigorsk \\ E-mail: borovski@rambler.ru
}

Статья посвящена основным жизненным вехам профессора, доктора фармацевтических наук, заслуженного деятеля науки РСФСР Беликова В.Г., внесшего большой вклад в развитие отечественного фармацевтического образования и науки, более 30 лет возглавлявшего ведущий фармацевтический вуз страны.

Ключевые слова: В.Г. Беликов, фармацевтическая химия, фармацевтическое образование и наука, Пятигорский фармацевтический институт.

29 августа 2015 г. исполнилось бы 90 лет выдающемуся ученому отечественной фармации, заслуженному деятелю науки РСФСР, профессору, доктору фармацевтических наук Владимиру Георгиевичу Беликову.

В.Г. Беликов родился в селе Степное Ставропольского края. По окончании школы был призван в ряды Красной Армии. С февраля 1943 г. В.Г. Беликов принимал участие в боях Великой Отечественной войны на Северо-Кавказском фронте. Осенью 1943 г. был направлен в Краснознаменную Каспийскую военную флотилию и прослужил в Военно-морском флоте еще 7 лет (рис. 1).
The article is devoted to basic life milestones of Professor, Doctor of Pharmaceutical Science, Honored Scientist of Russia V.G. Belikov, who made a great contribution to the development of domestic pharmaceutical education and science, more than 30 years headed the leading pharmaceutical institution of the country.

Keywords: V.G Belikov, pharmaceutical chemistry, pharmaceutical science and education, Pyatigorsk pharmaceutical institute.

В 1950 г. В.Г. Беликов поступил в Пятигорский фармацевтический институт.

В 1954 году за отличные успехи в учебе Министерство высшего и среднего образования СССР назначило ему стипендию им. И.В. Сталина. Сразу же по окончании института в 1955 г. был зачислен в аспирантуру на кафедру фармацевтической химии (рис. 3).

В 1954 году за отличные успехи в учебе Министерство высшего и среднего образования СССР назначило ему стипендию им. И.В. Сталина. Сразу же по окончании института в 1955 г. был зачислен в аспирантуру на кафедру фармацевтической химии (рис. 3). 


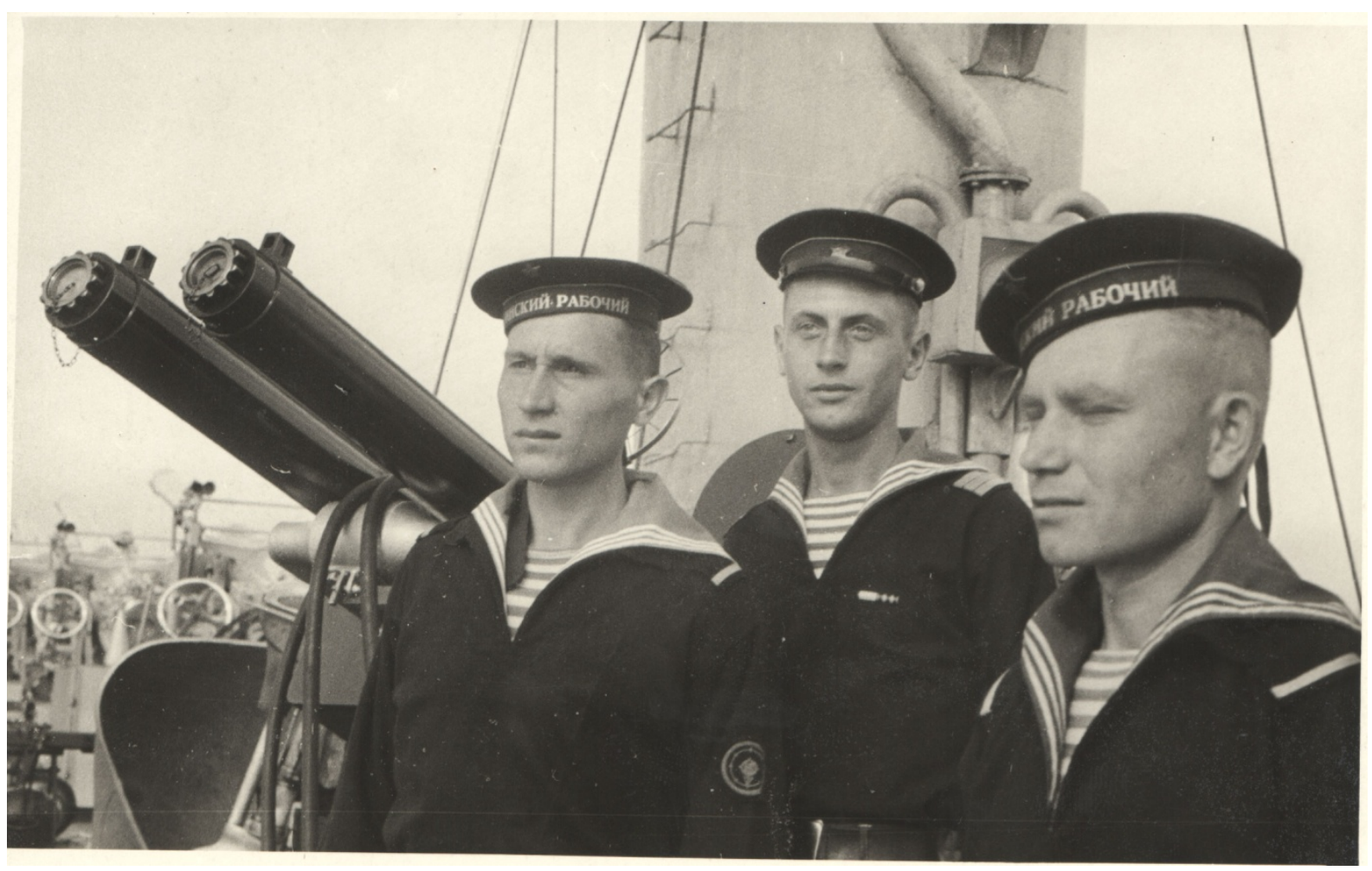

Рисунок 1 - Служюба в Красной армии и Военно-морском флоте (Сержсант В.Г. Беликов - в центре)

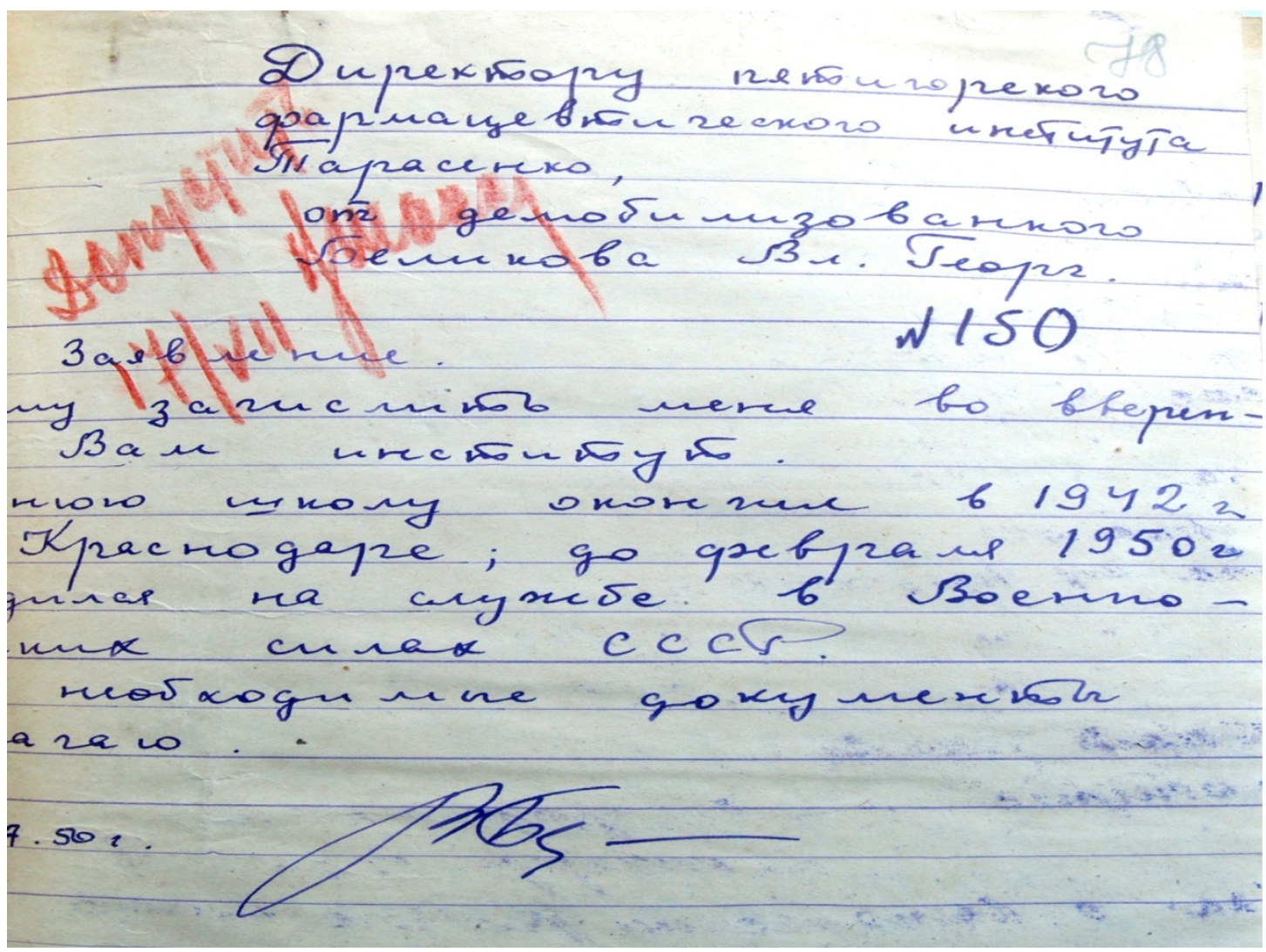

Рисунок 2 - Фрагмент заявления В.Г. Беликова о приеме в ПФИ в 1950 z. 


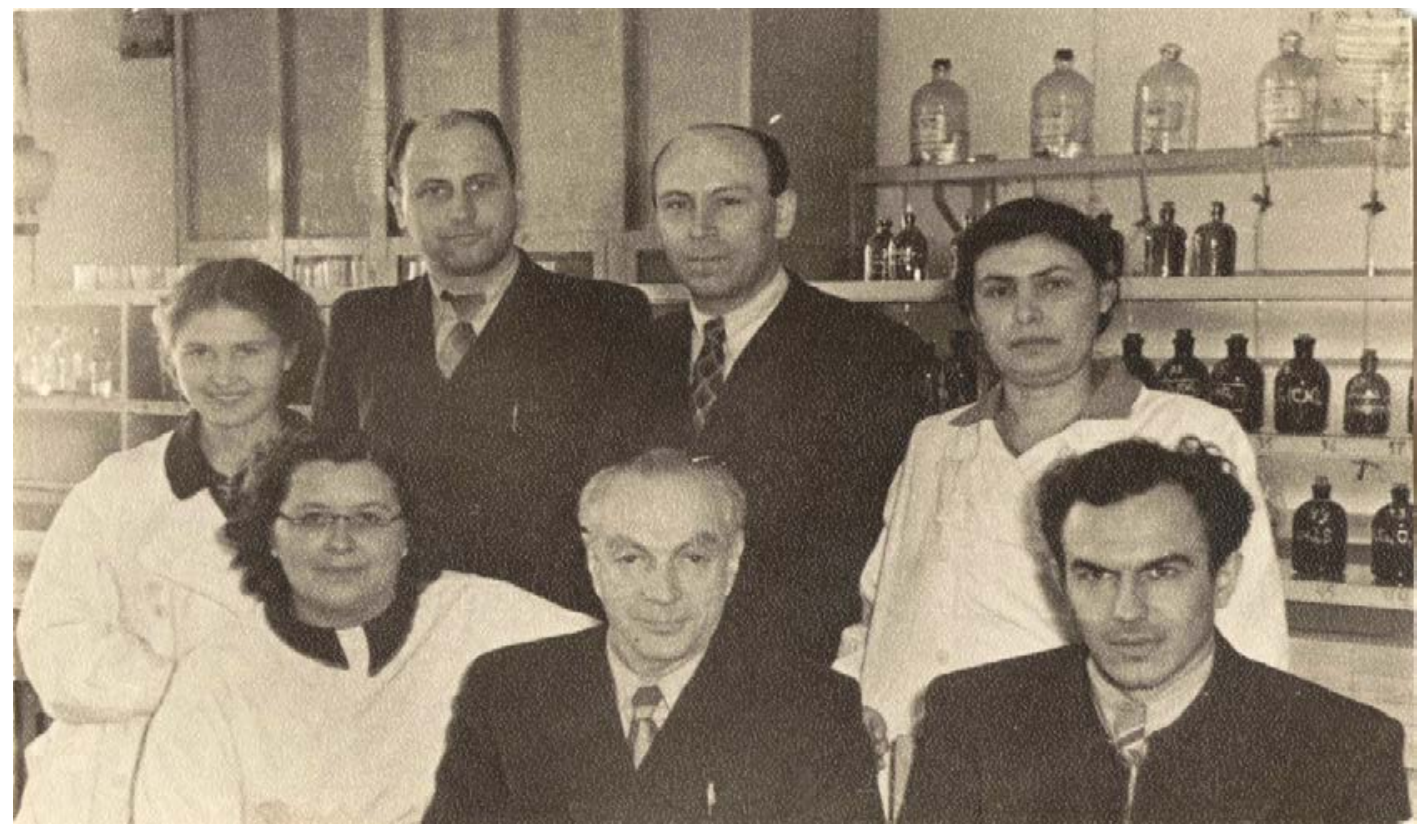

Рисунок 3 - В аспирантуре с научным руководителем доцентом В.Н. Берштейном (В.Н. Берштейн в нижнем ряду в центре, В.А. Бунаков справа, Г.М. Лукьянчикова слева, В.Г. Беликов - в верхнем ряду второй слева, рядом В.Е. Годяцкий) 1955 2.

Одновременно с учебой в аспирантуре Владимир Георгиевич работал в родном институте лаборантом, старшим лаборантом на различных кафедрах. В 1960 г. в стенах ВНИХФИ защитил кандидатскую диссертацию, с этого времени работал в должностях ассистента, доцента, а с 1972 года - профессора кафедры фармацевтической химии.
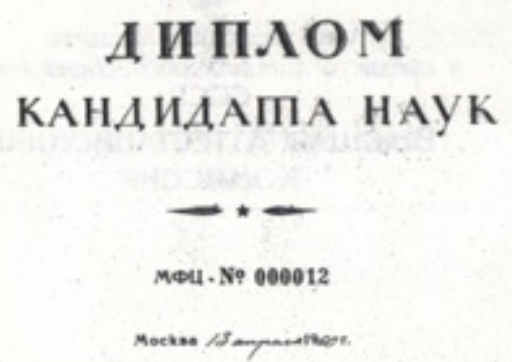

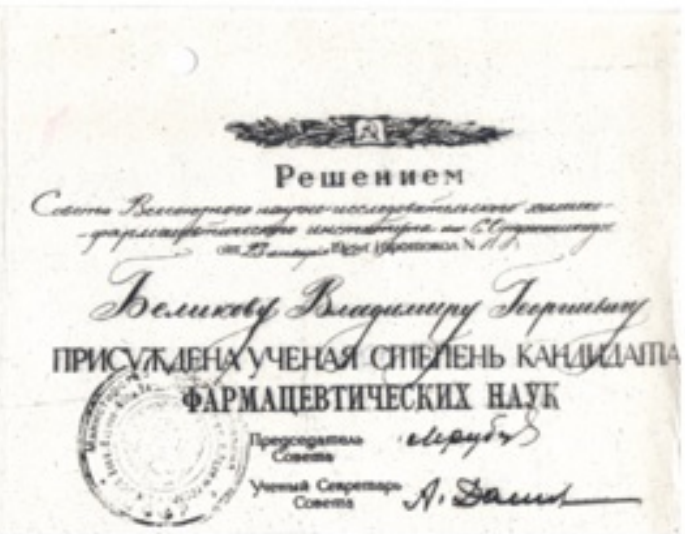

Рисунок 4 - Диплом кандидата фармацевтических наук В.Г. Беликова (1960 г.)

В 1961 г. В.Г. Беликова назначили на должность проректора по учебной и научной работе института. А в 1964 году он возглавил Пятигорский фармацевтический институт сначала как исполняющий обязанности ректора и через год - как полноправный ректор. На посту руководителя вуза он проработал 31 год. 


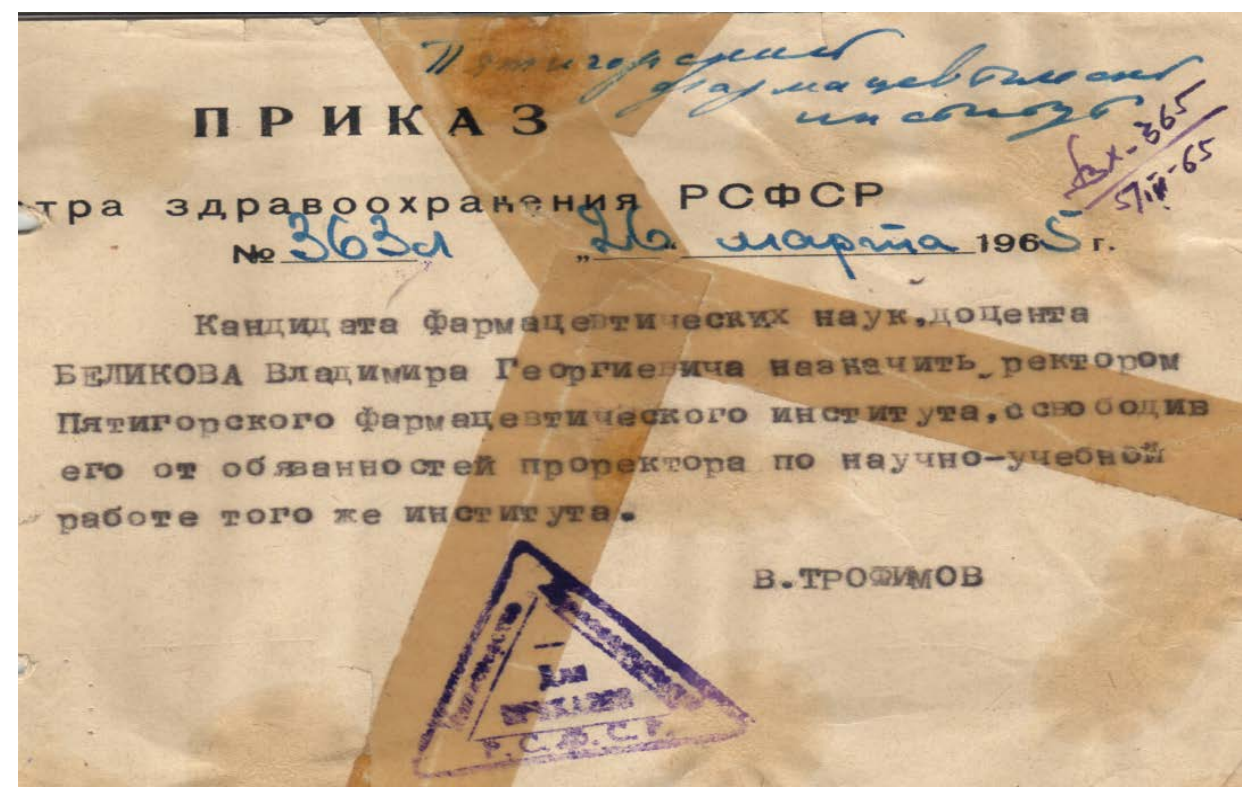

Рисунок 5 - Приказ Министра здравоохранения РСФСР № 363л от 26.03.1965 2. о назначении В.Г. Беликова на долюсность ректора Пятигорского фармацевтического института

Под его руководством Пятигорский фармацевтический институт стал одним из крупных фармацевтических вузов страны, была существенно расширена материальная база института: построен новый адми- нистративно-учебный корпус (рис. 6), три общежития, спортивно-оздоровительный лагерь, создан санаторий-профилакторий, студенческая поликлиника и первая в СССР учебно-производственная аптека.

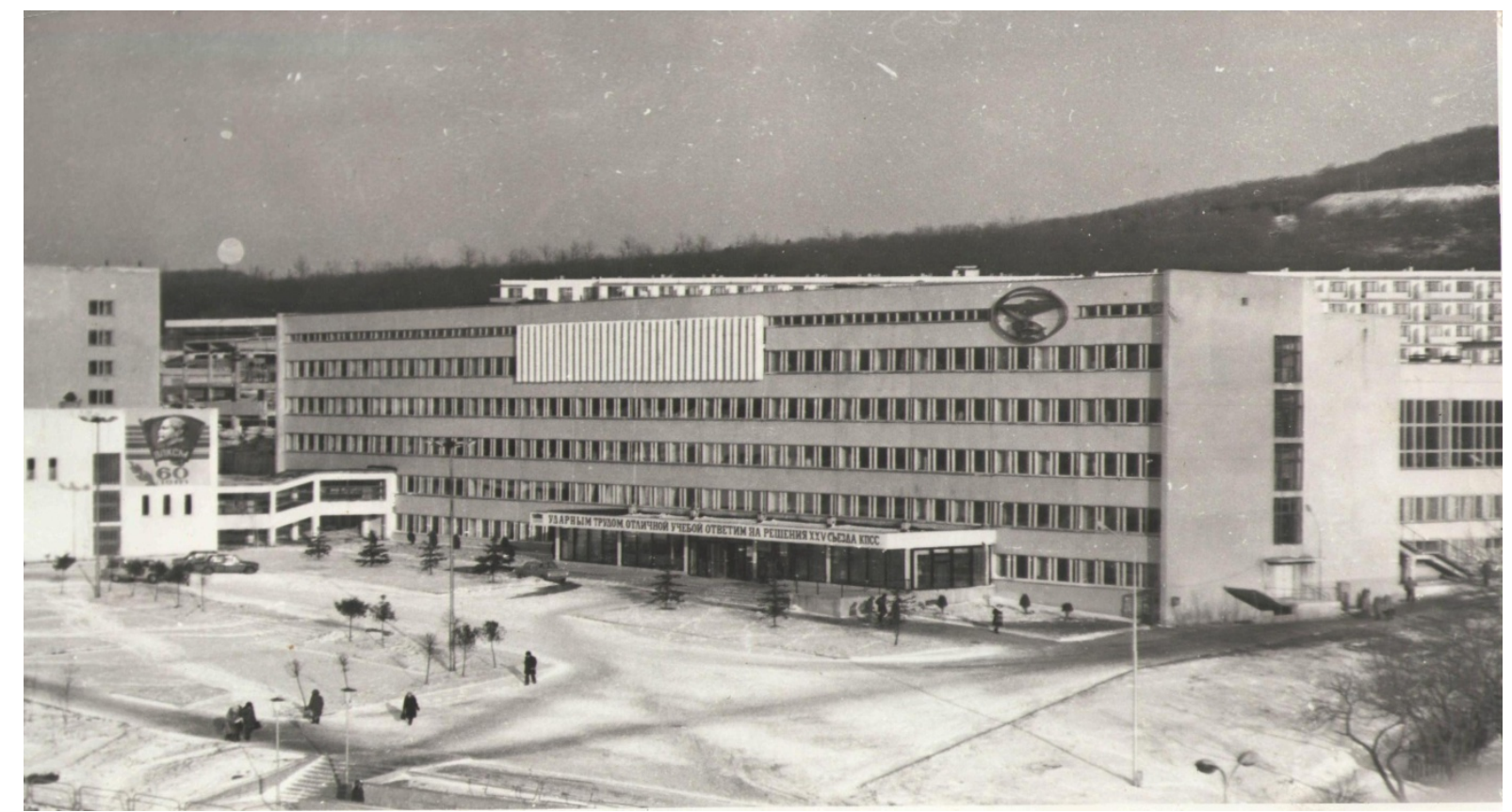

Рисунок 6-Новый административно-учебный корпус

Пятигорского фармацевтического института в 1978 г.

Большое внимание В.Г. Беликов уделял развитию фармацевтического образования. Под его руководством и при его непосредственном участии разработана концепция высшего фармацевтического образования.

Профессор В.Г. Беликов подготовил 5 изданий учебника «Фармацевтическая хи- 
мия», 2 издания справочника «Синтетические и природные лекарственные средства» и ряд учебных пособий по данному предмету. Кроме того, в авторском коллективе он принимал участие в издании практикумов по фармацевтической химии. Эти книги были изданы большими тиражами и рекомендованы для обучения студентов фармацевтических вузов и фармацевтических факультетов медицинских вузов СССР, затем - России и других стран СНГ. Кроме того, в списке опубликованных работ Владимира Георгиевича более 450 научных статей, 4 монографии, 15 авторских свидетельств и патентов, в том числе 3 зарубежных (США, ФРГ, Франция).

В 1970 г. В.Г. Беликов защитил диссертацию на соискание ученой степени доктора фармацевтических наук. Защита проходила в 1-м Московском медицинском институте им. И.М. Сеченова.

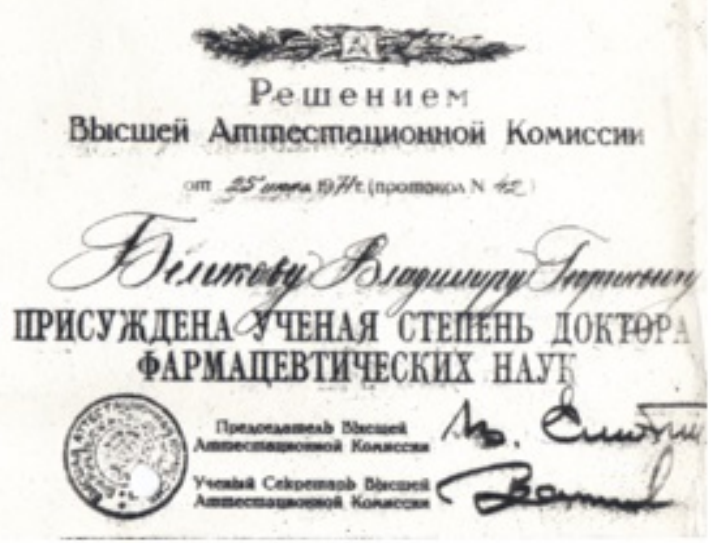

Рисунок 7 - Диплом доктора фармацевтических наук В.Г. Беликова (1971 г.)

Одновременно с работой над докторской диссертацией Владимир Георгиевич начал готовить аспирантов. В результате в последующие годы его учениками были выполнены 63 диссертации (4 докторские и 59 кандидатских), в том числе аспирантами из Вьетнама, Эфиопии, Йемена и Перу.

В течение 6 лет В.Г. Беликов работал экспертом Высшей аттестационной комиссии по специальности фармацевтическая химия и фармакогнозия. Кроме того, Владимир Георгиевич являлся вицепрезидентом Ассоциации медицинских и фармацевтических вузов России, членом совета Российского общества фармацевтов, членом редакционных советов ведущих научных изданий, таких как «Фармация» и «Химико-фармацевтический журнал»; входил в состав проблемных и методических комиссий при Министерстве здравоохранения. В.Г. Беликов также входил в совет ректоров края и Северо-Кавказского научного центра высшей школы, был избран действительным членом Российской экологической академии и международной ака- демии информатизации. Владимир Георгиевич принимал активное участие в подготовке, проведении и работе съездов всесоюзного, республиканского, международного уровней, в том числе Всемирного фармацевтического конгресса (г. Вашингтон, США), посвященных актуальным вопросам фармацевтического образования.

По инициативе В.Г. Беликова в Пятигорском фармацевтическом институте в 1985 г. был создан диссертационный совет, председателем которого он являлся по 2010 г. За это время в стенах вуза было успешно защищено 36 докторских и более 400 кандидатских диссертаций, что способствовало внесению значительного вклада в подготовку научных и педагогических кадров фармацевтических и медицинских вузов страны.

За годы его руководства ВУЗ подготовил более 18000 провизоров и около 1000 магистров фармации для 52 зарубежных стран. В 1994 г. Пятигорский фармацевтический институт, возглавляемый профессором В.Г. Беликовым, приобрел статус ака- 
демии, что явилось признанием заслуг коллектива и руководителя вуза в области высшего фармацевтического образования.

С 1995 г. по 2012 г. В.Г. Беликов работал советником ректората. Кроме того, с 1972 по 2006 год он являлся заведующим кафедрой фармацевтической химии, а затем, вплоть до последних дней, профессором этой же кафедры. Как говорил и писал сам профессор В.Г. Беликов: «Так и работал всю жизнь с одной записью в трудовой книжке от 1 сентября 1950 года, менялись лишь должности.... Пока я работаю, я живу...» [1].

Правительство высоко оценило вначале боевую, а затем трудовую, научную и общественную деятельность В.Г. Беликова. Владимир Георгиевич был награжден орденами Отечественной войны II степени, Трудового Красного Знамени и «Знак Почета», 30 медалями и двумя почетными званиями: «Заслуженный деятель науки РСФСР» и «Лауреат премии Правительства РФ в области образования» (рис. 8).

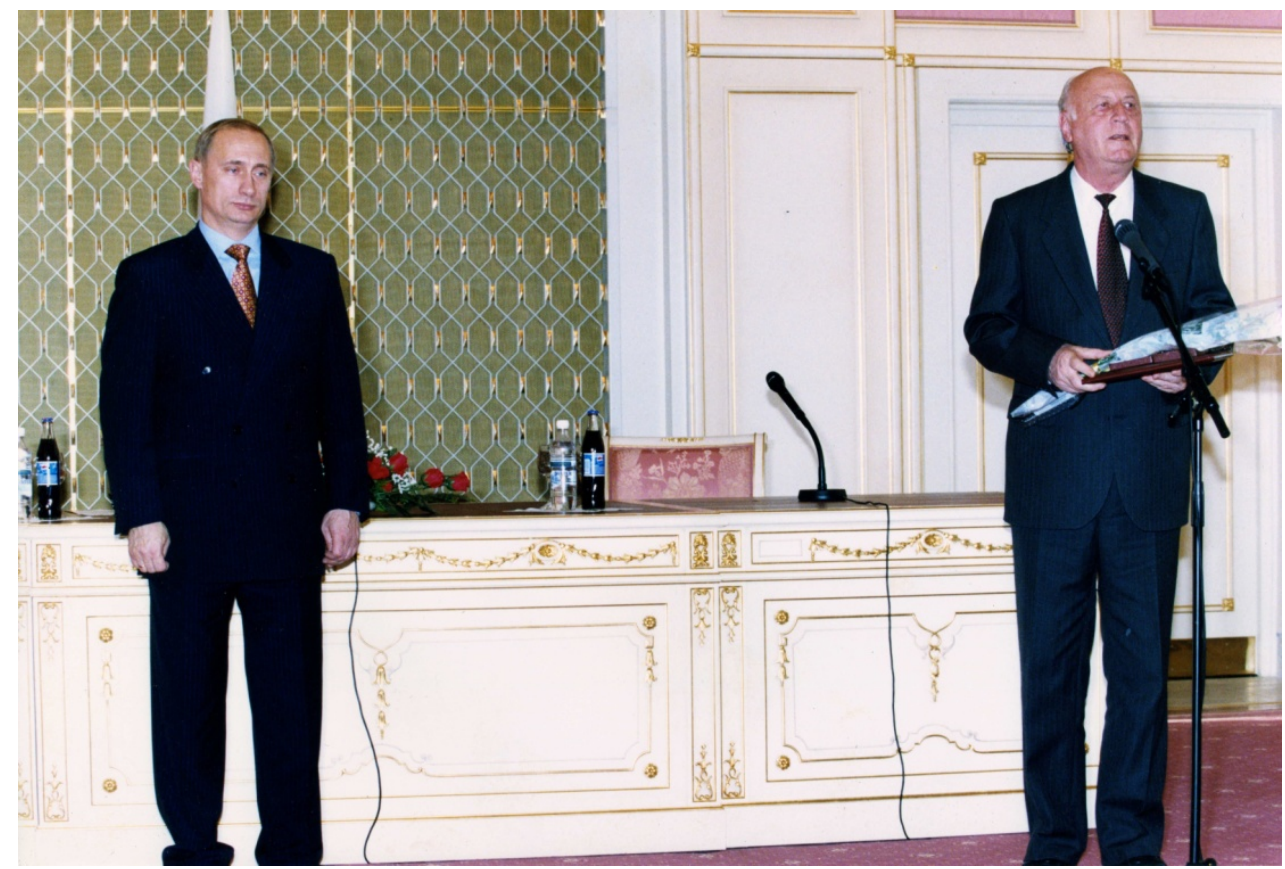

Рисунок 8-Вручение премии Правительства РФ В.Г. Беликову (1999 2.)

Вся жизнь Владимира Георгиевича Беликова - «это скромное мужество русского интеллигента», как отметил В.В. Путин, вручая ему премию Правительства РФ в области образования в 1999 году [1]. Вручение премии в Кремле явилось свидетельством высокой оценки проделанной им научной и учебно-методической работы.

«Главное в человеке - порядочность: всегда делать то, что обещаешь, и не обещать того, чего сделать не можешь»

проф. В.Г. Беликов

\section{Библиографический список}

1. Беликов В.Г. Судьбы моей нелегкие ступени: монография. - Пятигорск, 2010. - 90 с.

Боровский Борис Владимирович - кандидат фармацевтических наук, преподаватель кафедры неорганической, физической и коллоидной химии Пятигорского медикофармачевтического института - филиала ГБОУ ВПО ВолгГМУ Минздрава России. E-mail: borovski@rambler.ru 
Ларский Михаил Владимирович - кандидат фармачевтических наук, старший преподаватель кафедры фармачевтического товароведения, гигиены и экологии Пятигорского медико-фармачевтического института - филиала ГБОУ ВПО ВолгГМУ Минздрава России. Область научных интересов: товароведческий анализ ассортимента и потребительных свойств медицинских и фармачевтических товаров. E-mail: larsky.mikhail@gmail.com

Фролова Ольга Олеговна - кандидат фармацевтических наук, ведущий специиалист отдела аспирантуры и докторантуры Пятигорского медико-фармацевтического института - филиала ГБОУ ВПО ВолгГМУ Минздрава России. 